\title{
The path to minimizing instability in developmental dysplasia of the hip: is Capsulorrhaphy a necessity or a futile habit?
}

Ramin Zargarbashi ${ }^{1}$ (D), Mohammadreza Bozorgmanesh², Behnam Panjavi ${ }^{1}$ and Fardis Vosoughi ${ }^{3^{*}}$ (D)

\begin{abstract}
Background: To evaluate and quantify the intraoperative effect of capsulorrhaphy on the deep seating of femoral head within the acetabulum as measured by medial joint space, a surrogate measure of acetabular-head contact.

Methods: In order to determine the exact effect of capsulorrhaphy, we prospectively scrutinized a consecutive sample of 18 patients with unilateral dysplastic hips aging $>18$ months and followed them for a period of at least 12 months. The procedure of open reduction is described in detail. Two pediatric orthopedists carried out the operations from August 2014 to January 2019 at a tertiary pediatric hospital. Intraoperatively, AP radiographs of the pelvis were obtained before and after capsulorrhaphy. The distance between the inferomedial edge of the proximal femoral metaphysis and the lateral edge of the obturator foramen was recorded. To determine if there were differences in medial joint space due to capsulorrhaphy, a generalized linear model was run on the study sample. All patients were followed for at least 12 months to determine the rate of re-dislocation.

Results: Mean age ( \pm standard deviation) of the participants was $37.5( \pm 24.7)$ months. All cases underwent Salter osteotomy, 5 cases needed femoral shortening (27.8\%) and none needed derotational osteotomy. Capsulorrhaphy lead to a statistically significant decrease in the mean medial joint space from $1.59 \mathrm{~cm}$ before $(95 \% \mathrm{Cl}: 1.12-2.05)$ to $0.76 \mathrm{~cm}$ after (95\% Cl: 0.50-1.02) the capsulorrhaphy $(P<0.001)$. When we took the effect of age into account the corresponding figures were 1.47 (95\% Cl: 1.22-1.75) and 0.67 (95\% Cl: $0.39-0.94)$, respectively $(\mathrm{P}<0.001)$. After follow up periods of 1 to 5.5 years, none of the patients experienced instability or re-dislocation.

Conclusions: Capsulorrhaphy, independently, of age was associated with a 1-cm decrease in the mean medial hip joint space and a more deeply seated femoral head. Furthermore, this study presents a successful experience with capsulorrhaphy to prevent hip instability.
\end{abstract}

Keywords: DDH, Developmental hip dysplasia, Capsulorrhaphy, Medial joint space

\footnotetext{
* Correspondence: fardis.vosoughi@gmail.com

${ }^{3}$ Department of Orthopaedic and Trauma Surgery, Jalal Street, Shariati Hospital and school of medicine, Tehran University of Medical Sciences, Tehran, Iran

Full list of author information is available at the end of the article
}

(c) The Author(s). 2021 Open Access This article is licensed under a Creative Commons Attribution 4.0 International License, which permits use, sharing, adaptation, distribution and reproduction in any medium or format, as long as you give appropriate credit to the original author(s) and the source, provide a link to the Creative Commons licence, and indicate if changes were made. The images or other third party material in this article are included in the article's Creative Commons licence, unless indicated otherwise in a credit line to the material. If material is not included in the article's Creative Commons licence and your intended use is not permitted by statutory regulation or exceeds the permitted use, you will need to obtain permission directly from the copyright holder. To view a copy of this licence, visit http://creativecommons.org/licenses/by/4.0/. The Creative Commons Public Domain Dedication waiver (http://creativecommons.org/publicdomain/zero/1.0/) applies to the data made available in this article, unless otherwise stated in a credit line to the data. 


\section{Background}

A congruent stable hip is the result of parallel geometrical development of the proximal femur and the acetabulum. In other words, it is a product of concurrent acetabular and proximal femoral growth from their corresponding growth plates [1]. Absence of appropriate contact between the acetabulum and proximal femur leads to an incongruent joint. The hip joint may not develop normally if it doesn't reach congruity by walking age $[2,3]$. Developmental dysplasia of the hip (DDH) falls somewhere in a spectrum of physical and imaging findings. Early diagnosis and treatment of DDH is critical in achieving the best possible functional outcome [3]. The acetabular changes in DDH have been described and well recognized before. Recently, we have gained better understanding of the changes in the femoral head. Patients who fail after closed treatment, need an open reduction. Despite substantial research, high-quality comparative studies continue to be lacking and the treatment of DDH is mainly based on the clinical experience of the treating surgeon [3]. This variability in opinion became evident in a 2018 survey of EPOS and POSNA members on their preferred treatment methods for DDH [4].

Principals of surgical treatment of DDH, however, always include reduction and stabilization. These principals could be applied by conservative or surgical means. Conservative measures are more effective before the age of 6 months and include a variety of techniques such as the Pavlik harness splint [5], the Tubigen hip flexion splint [6], closed reduction plus spica casting and Sommerville- Petit method of traction [7]. According to the 2018 DDH survey, in spite of marked disparity between surgeons, closed reduction is usually not favored prior to 3 months or open reduction before 6 months of age [4]. Surgical Stabilization might be required in cases with failed conservative treatment, residual dysplasia or older children with neglected DDH. Surgical stabilization is generally achieved by a reduction into a near anatomical position and perhaps a complementary capsulorrhaphy. In fact, some surgeons do not believe capsulorrhaphy to be necessary $[8,9]$. Others, perform capsulorrhaphy as a routine adjuvant to open reduction [10-14]. Theoretical pros and cons have been proposed with few studies, attempting to examine the clinical relevance of the capsulorrhaphy [14]. Furthermore, correction of bony abnormalities such as excessive femoral anteversion or length and acetabular dysplasia might be indicated to prevent instability. Surgical correction of bone deformities should be aimed at securing the stabilization [12].

Treatment of DDH hinges heavily on attempting to keep the femoral head within the acetabulum (concentric reduction), thereby inducing acetabular development to contain the femoral head. Acetabular remodeling requires pressure of the well-seated femoral head against the acetabulum $[15,16]$. Magnetic resonance imaging has been shown to have a role in the evaluation of joint congruency [17]. However, it is expensive with limited access in developing countries and also is not available intraoperatively $[18,19]$. The width of the medial joint space on a standard AP radiograph has been widely accepted as an indicator of stability of the reduction [19]. Normal radiographic appearance, therefore, could be indirectly translated to improved outcome. Hence, clinical relevance of different treatments could be assessed on the basis of the extent to which they can restore normal radiographic appearance of the hip joint.

Within the frames of this paradigm, we hypothesized that capsulorrhaphy can improve the acetabular-head contact among patients treated surgically for DDH. Hence, the primary objective of this study is to determine if capsulorrhaphy decreases medial joint space and thereby improves acetabular-head contact. Secondary objectives are to determine if capsulorrhaphy caused limitation in hip range of motion or avascular necrosis of the femoral head. Moreover, we intend to present our experience in attempting to achieve hip stability using capsulorrhaphy as an adjuvant to open reduction among other methods.

\section{Methods \\ Participants}

The study was approved by the Institutional Review Board of Tehran University of Medical Sciences. Informed written consent was obtained from the patients' parents or legal guardians. We prospectively reviewed a consecutive sample of 20 patients with unilateral DDH aging $>18$ months. Non-idiopathic cases (e.g., due to paralytic disorders or congenital syndromes) were excluded from the study (2 cases). The remaining 18 patients were studied. Demographic data were collected using a predetermined questionnaire.

\section{Procedure}

The procedure included a one-stage open reduction and Salter osteotomy, combined with femoral shortening or derotational osteotomy if necessary, by two surgeons, from August 2014 to January 2019 at a tertiary pediatric hospital.

\section{Radiologic evaluation}

Intraoperatively, simple AP radiographs of the pelvis were obtained with the child in the supine position. Care was taken to position the child with the legs parallel and to avoid rotation of the pelvis and hips. The first radiograph was taken after the reduction of femoral head, Salter osteotomy, depleting the acetabulum of pulvinar fat and releasing the transverse ligament, just before 
capsulorrhaphy. The second radiograph was taken just after capsulorrhaphy. Having considered a magnification marker (surgical blade), we measured the distance between the inferomedial edge of the proximal femoral metaphysis and the lateral edge of the obturator foramen (Fig. 1). This distance was used as a surrogate measure to quantify the extent to which femoral head was deeply seated within the acetabulum.

\section{Surgical technique}

We used a "bikini" incision extended distally for $2 \mathrm{~cm}$ beyond the anterior inferior iliac spine (AIIS). The external oblique muscle was shaved from the iliac crest, to allow splitting the iliac apophysis down to the bone. Blunt dissection of the tensor-Sartorius interval was performed. Tendinous part of the iliopsoas was sectioned to achieve adequate medial exposure. After gaining good exposure, capsulotomy was performed in a Vshaped manner leaving a $5-\mathrm{mm}$ margin of capsule. The ligamentum teres, the fibrofatty tissue and transverse ligament were removed to provide a reducible joint. With the hip dislocated, nonabsorbable sutures were

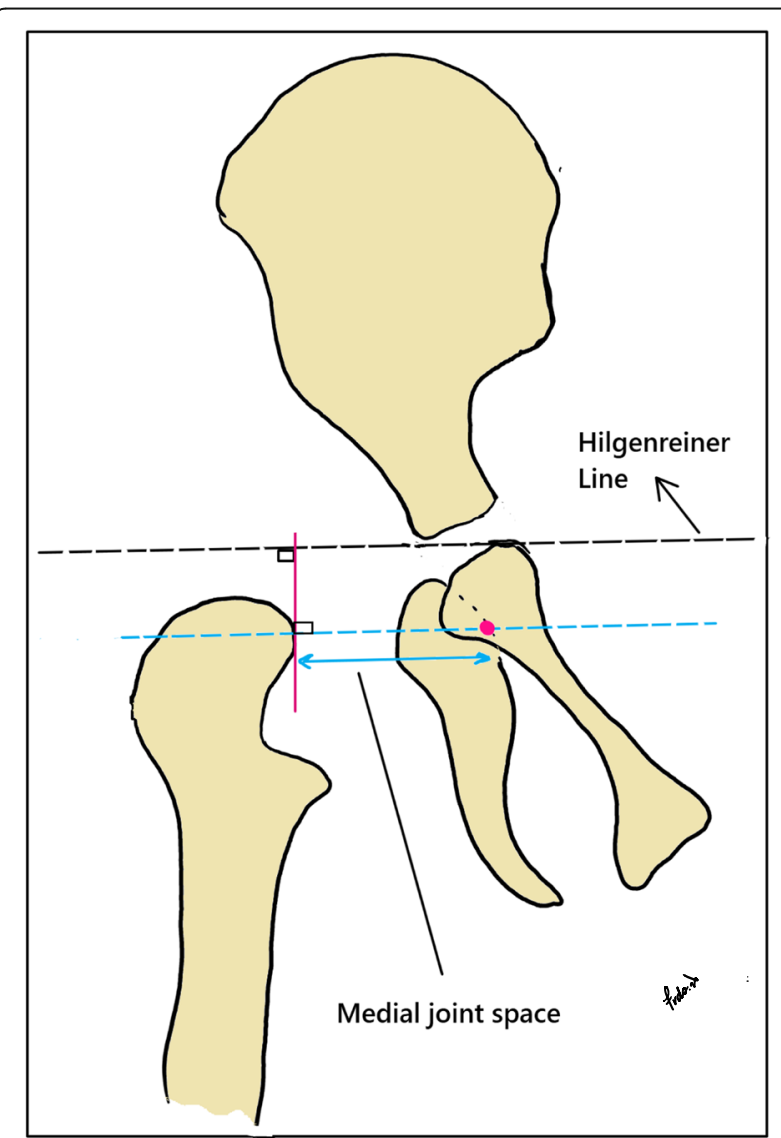

Fig. 1 Schematic drawing of the medial hip joint space. This illustration is the sole work of the corresponding author (F.V.), presented for the purpose of publication in the current study] passed through the medial portion of the capsule. Next the hip was reduced, and sutures were passed through the superolateral segment of the capsule. Decision was made to perform innominate osteotomy and/or femoral shortening. Only after performing osteotomies and reducing the joint, was the joint capsule imbricated by tying the suture knots. An anteroposterior radiograph was taken by $\mathrm{C}$-arm prior to and after the capsulorrhaphy. After repairing the iliac apophysis, rectus femoris, and the wound, a one-and-half hip Spica cast was applied postoperatively for 6 weeks, after which it was changed to a broomstick cast for 4 weeks.

\section{Statistical analysis}

The data are presented as mean (SD) and frequency (\%) for continuously- and categorically-distributed variables respectively. As a normal distribution was not seen, a non-parametric test seemed more appropriate. Wilcoxon signed-rank test was used to compare means. To determine if there were differences in medial joint space due to capsulorrhaphy a general linear model was run on a sample of 18 participants. All statistical analysis was performed with the use of SPSS software version 25 (IBM Corp.). $P$-value less than 0.05 was considered significant.

\section{Results}

Baseline characteristics of the participants are shown in the Table 1. Mean age (SD) was 37.5 (24.7) months (range: 18-96). 3 of them were boys (16.7\%). Patients had no other underlying conditions. All the cases

Table 1 Patient characteristics

\begin{tabular}{ll}
\hline Patient Characteristics & Frequency (\%) \\
\hline Age at the time of operation (in months) & \\
Mean \pm S.D. (min-max) & $37.5 \pm 24.7$ (18-96) \\
Age groups (in years) & $11(61.1)$ \\
$<3$ & $5(27.8)$ \\
$3-6$ & $2(11.1)$ \\
$>6$ & \\
Sex & $3(16.7)$ \\
Male & $15(83.3)$ \\
Female & \\
Type of surgery & $18(100)$ \\
Salter Osteotomy & $5(27.8)$ \\
Femoral Shortening & None \\
Femoral derotational osteotomy & \\
Mean Medial Joint Space values & $1.59(1.12-2.05)$ \\
Before Capsulorrhaphy (95\% Cl) & $0.76(0.50-1.02)$ \\
After Capsulorrhaphy (95\% Cl) & $0.83(0.54-1.11)$ \\
Before-After difference (95\% Cl) & $<0.001$ \\
Power analysis value & \\
\hline
\end{tabular}


underwent Salter osteotomy, 5 cases (27.8\%) needed femoral shortening and none needed derotational osteotomy. Medial joint space values for all patients are given in Table 2. A statistically significant decrease in mean medial joint space is seen from 1.59 just before capsulorrhaphy (95\%CI: $1.12-2.05)$ to 0.76 (95\%CI: $0.50-1.02)$ afterwards $(P<0.001)$. An example has been shown in Fig. 2. Moreover, medial joint space values for all patients are depicted as clustered bar charts (Fig. 3). When we took the effect of age into account, the corresponding figures were 1.47 (95\%CIs: $1.22-1.75)$ and 0.67 (95\%CIs: $0.39-0.94)$, respectively $(\mathrm{P}<0.001)$. Also, age did not have a significant effect on the change of medial joint space $(P=0.26)$.

Mean medial joint space values were also calculated specifically among the patients who had not underwent femoral osteotomy (13 patients). Mean medial joint space of 1.61 (95\%CIs: $1.05-2.16)$ in this group decreased to 0.80 (95\%CIs: 0.48-1.12) after capsulorrhaphy, showing a mean decrease of 0.81 (95\%CIs: 0.451.16) centimeters.

The mean duration of follow up was 2.3 years (1.1) ranging from 1 to 5.5 years. Patient evaluations in the follow up period, revealed no signs of instability, subluxation or re-dislocation after at least 12 months from surgery. All 18 patients achieved symmetric full hip range of motion with full extension. No case of avascular

Table 2 Medial joint space values for each patient. Cases marked with a star, underwent femoral shortening

\begin{tabular}{|c|c|c|c|}
\hline \multirow[t]{2}{*}{ ID } & \multirow{2}{*}{$\begin{array}{l}\text { Age } \\
\text { (months) }\end{array}$} & \multicolumn{2}{|l|}{ Medial joint space $(\mathrm{cm})$} \\
\hline & & Before capsulorrhaphy & After capsulorrhaphy \\
\hline $1^{*}$ & 60 & 0.20 & 0.10 \\
\hline $2^{*}$ & 96 & 2.60 & 1.40 \\
\hline 3 & 30 & 1.80 & 0.20 \\
\hline 4 & 20 & 1.50 & 0.80 \\
\hline 5 & 36 & 2.60 & 0.70 \\
\hline 6 & 30 & 1.80 & 0.80 \\
\hline 7 & 37 & 3.80 & 2.10 \\
\hline 8 & 24 & 1.50 & 1.00 \\
\hline $9^{*}$ & 24 & 2.30 & 0.80 \\
\hline 10 & 36 & 0.90 & 0.70 \\
\hline 11 & 18 & 1.80 & 1.00 \\
\hline 12 & 96 & 2.10 & 1.40 \\
\hline $13^{*}$ & 60 & 0.50 & 0.10 \\
\hline $14^{*}$ & 18 & 2.10 & 0.90 \\
\hline 15 & 24 & 1.40 & 0.80 \\
\hline 16 & 24 & 0.50 & 0.30 \\
\hline 17 & 24 & 0.40 & 0.20 \\
\hline 18 & 18 & 0.80 & 0.40 \\
\hline
\end{tabular}

necrosis or osteoarthritis was seen during the follow up periods.

\section{Discussion}

Herein, this study shows that, as a part of open reduction of the DDH, capsulorrhaphy can significantly improve deep-seating of the femoral head within the acetabulum (Fig. 4).

Capsulorrhaphy has long been proposed as a part of the surgical treatment of DDH [20] and inadequate capsulorrhaphy has been reported as a factor predisposing to failure of the initial open reduction along with other factors such as inadequate inferior capsular release [21-28].

Iyetin et al. have recently introduced a modified surgical approach to the hip in which capsulorrhaphy is not required. They obtained excellent or good results in 93\% of the patients treated. The authors, based on data from a period of 5-year follow-up, concluded that treatment for DDH using this modified medial approach during early childhood is an effective and reliable method with low complication rates and that great success in radiologic and clinical outcomes could be expected [9]. Whether this finding could be extrapolated to older patients remains to be elucidated. This study presents a wide age range. In Iran, there are numerous neglected cases of DDH who present to the pediatric orthopedist very late. The fact that capsulorrhaphy could help the deep sitting of the femoral head even in these advanced cases is an argument that could be made in favor of capsulorrhaphy (Fig. 3). Currently, it is recommended that when the diagnosis has been made late, reduction of the hip must be combined with capsulorrhaphy along with corrective procedures on the femur and acetabulum to stabilize the reduction, with the goal of optimizing hip stability and minimizing the risk of residual dysplasia [12]. In the current study, the favorable effect observed on the acetabular-head contact, as indicated by deepseating of the femoral head, due to capsulorrhaphy resisted adjustment for the confounding effect of age. This finding implies that the favorable effect of capsulorrhaphy on improving acetabular-head contact is independent of age.

The surgeons who support capsulorrhaphy would argue that it helps obtain and maintain a acetabularhead contact. Other surgeons, however, that recommend against capsulorrhaphy believe that not only is the capsulorrhaphy ineffective in obtaining and maintaining reduction, but also it may put the hip joint in jeopardy in terms of range of motion [29].

The Salter-type capsulorrhaphy is performed by excision of the redundant superolateral and posterior pouch of capsule to minimize the chance of re-dislocation. Proper excision and repair leaves no space into which the head could dislocate or subluxate [30]. 


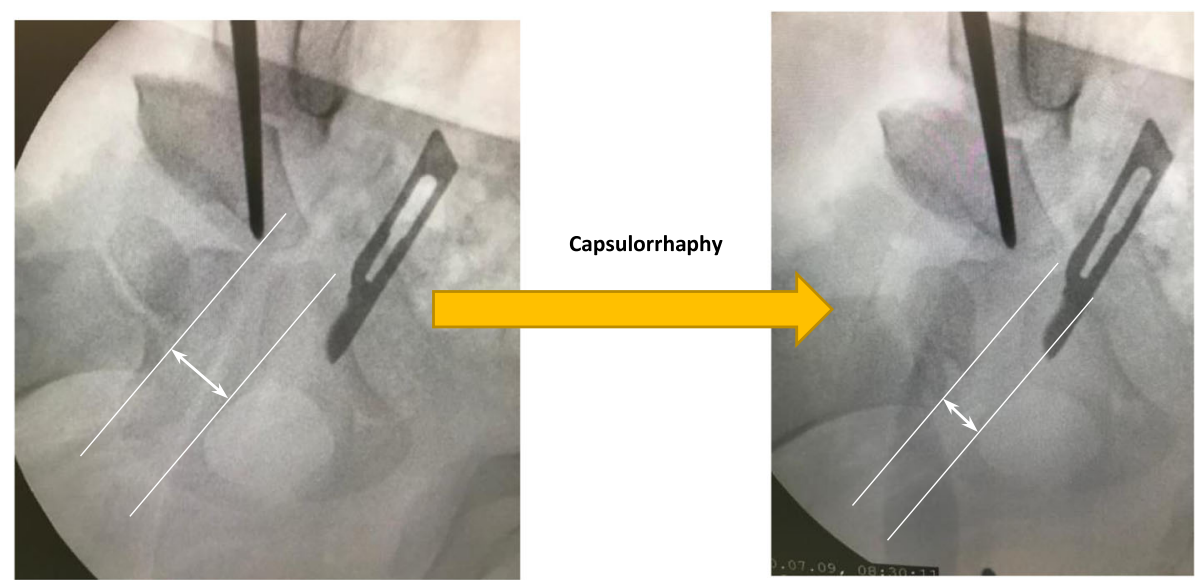

Fig. 2 Medial joint space before (left) and after (right) capsulorrhaphy

Capsulorrhaphy and capsulectomy were prospectively compared by Lejman. They investigated a sample of 39 patients with DDH. The surgical technique included innominate osteotomy, and femoral shortening and derotational osteotomy. During follow-up, avascular necrosis developed in one capsulorrhaphy patient. Postoperative re-dislocation was reported to occur in three capsulorrhaphy and no capsulectomy patients. Three capsulorrhaphy and three capsulectomy patients had acetabular dysplasia. Neither capsulorrhaphy nor capsulectomy were found to produce superior hip motion at the last examination. The authors were convinced based on these findings to continue capsulectomy in conjunction with open reduction for DDH [14]. In the current study no case of avascular necrosis occurred and the only patients who couldn't achieve full hip motion, were known cases of arthrogryposis.

The findings of the current study need to be interpreted in light of the limitations and strengths.
Regarding generalizability of the results there are serious limitations in this study. There are a number of limitations to this study. An argument could be made as to the effect of femoral shortening and/or derotational osteotomy on the reported decrease in medial joint space. None of our patients underwent derotational osteotomy. Significant decrease was still apparent in the 13 patients who did not undergo femoral shortening osteotomy, nevertheless, in order to determine the exact effect, larger sample sizes would be needed. We reported no case of redislocation, instability, avascular necrosis or osteoarthritis. This absence of complications cannot be generalized due to the relatively low number of cases. The low sample size in this study is partly due to the fact that we only included unilateral DDH cases, so that we could compare postoperative range of motion to the contralateral side and determine if full motion had been restored.

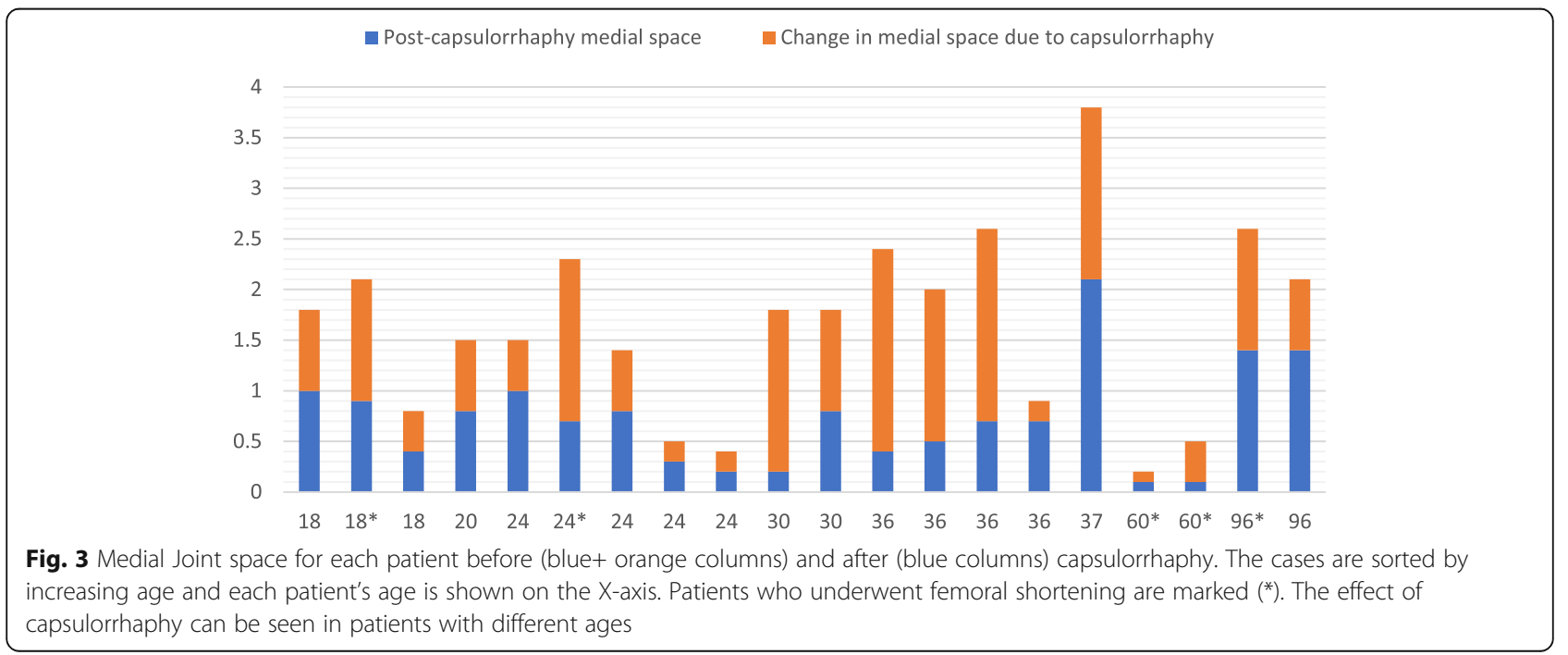




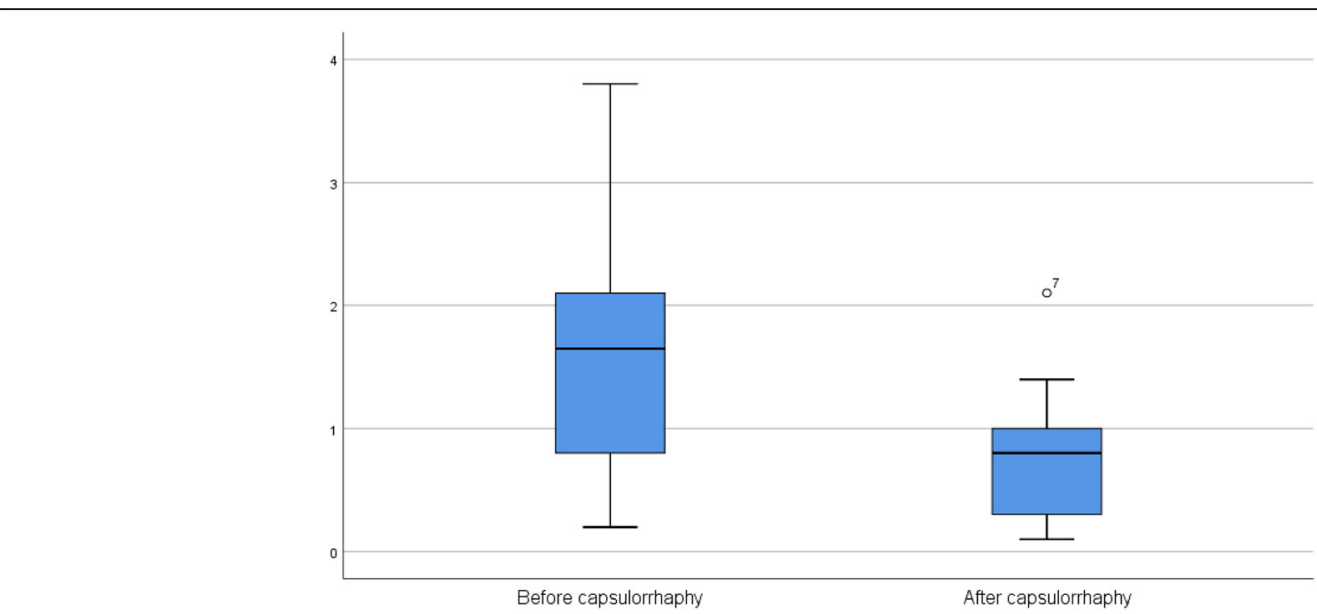

Fig. 4 stem-and-leaf plot for mean pre-capsulorrhaphy and post-capsulorrhaphy medial joint space

A limitation of this study is the use of scalpels as magnification markers. In fact we used the Conn's method of "placing a marker of known diameter beside the thigh at the level of the femur" [31]. Precise placement of external calibration markers (ECMs) is of paramount importance in this method [32]. A spherical marker would have been a more reliable choice. Nevertheless, in order to avoid measurement errors, extreme care was taken to maintain the patient, the $\mathrm{C}$-arm and the marker in the exact same position and angle, so that the only difference between the two images was performing capsulorrhaphy.

Regarding study design the most powerful design would be to compare results in patients who have undergone capsulorrhaphy with those who haven't. It might have been unethical not to perform capsulorrhaphy in a group of children. Howbeit, to overcome this flaw, we compared medial joint space before and after capsulorrhaphy to show its radiographic effect.

It is generally accepted that "the only guarantee of a lifetime of normal hip function is a completely normal radiographic appearance of the hip" [33]. Obtaining a completely normal radiographic appearance of the hip is a rationale, based upon which the treatment of DDH has been developed and still continues to develop. Herein, no claim can be made as to the clinical efficacy of capsulorrhaphy, as there were no control groups to compare re-dislocation rate and complications. Further long-term studies with larger sample sizes will be required before accepting the capsulorrhaphy as the sine qua non to the surgical treatment of the DDH. The strength of the current study lies in the statistical power that was large enough to enable us adjust in the effect of age. We used appropriate statistical method that is robust to the violation of the regression presumptions of normality on the distribution of the medial joint space measures as well as that of linearity in the association. When we log- transformed the measures to obtain more normallydistributed measures, the results remained essentially the same. We, therefore, decided to report the more parsimonious model without transformation.

\section{Conclusion}

In conclusion, according to the current study capsulorrhaphy independently of age is associated with a decrease in the mean medial hip joint space and a more deeply seated femoral head. It seems that capsulorrhaphy is an effective technique in minimizing instability in the developmental dysplasia of the hip.

\section{Abbreviations}

DDH: Developmental Dysplasia of the Hip; SD: standard deviation; ECM: external calibration marker

\section{Acknowledgements \\ None.}

Authors' contributions

RZ helped in designing the study, data acquisition and interpretation, drafting the paper and performed surgeries. MB helped with study design, analyzing the data and writing the manuscript. BP helped in study design, helped in performing surgeries and measurements. FV helped with data acquisition and interpretation, revising the manuscript, preparing the final version and submitting the manuscript. All authors have read and approved the final submitted manuscript.

\section{Funding}

No funding was received for the current study.

Availability of data and materials

The datasets used and/or analyzed during the current study are available from the corresponding author on reasonable request.

Ethics approval and consent to participate

The study was approved by the Institutional Review Board of Tehran University of Medical Sciences. Written informed consent was obtained from the patients' parents or legal guardians.

Consent for publication Not Applicable. 


\section{Competing interests}

All authors declare that there were no competing interests for this study.

\section{Author details}

'Department of Pediatric Orthopedics, Children's Medical Center and school of medicine, Tehran University of Medical Sciences, Tehran, Iran.

${ }^{2}$ Department of Orthopedic Surgery, Vali-e-Asr Hospital, Arak University of Medical Science, Arak, Iran. ${ }^{3}$ Department of Orthopaedic and Trauma Surgery, Jalal Street, Shariati Hospital and school of medicine, Tehran University of Medical Sciences, Tehran, Iran.

Received: 9 October 2020 Accepted: 9 February 2021

Published online: 17 February 2021

\section{References}

1. Lee MC, Eberson CP. Growth and development of the child's hip. Orthop Clin North Am. 2006;37(2):119-32 v.

2. Guille JT, Pizzutillo PD, MacEwen GD. Development dysplasia of the hip from birth to six months. J Am Acad Orthop Surg. 2000;8(4):232-42.

3. Schwend RM, Shaw BA, Segal LS. Evaluation and treatment of developmental hip dysplasia in the newborn and infant. Pediatr Clin N Am. 2014;61(6):1095-107.

4. Alves C, Truong WH, Thompson MV, Suryavanshi JR, Penny $C L$, Do HT, et al. Diagnostic and treatment preferences for developmental dysplasia of the hip: a survey of EPOS and POSNA members. J Child Orthop. 2018;12(3):23644.

5. Cashman J, Round J, Taylor G, Clarke N. The natural history of developmental dysplasia of the hip after early supervised treatment in the Pavlik harness: a prospective, longitudinal follow-up. J Bone Joint Surg Br. 2002;84(3):418-25.

6. Pavone V, Testa G, Riccioli M, Evola FR, Avondo S, Sessa G. Treatment of developmental dysplasia of hip with Tubingen hip flexion splint. J Pediatr Orthop. 2015;35(5):485-9.

7. Cigala F, Lotito FM, De Felice D. "CONSERVATIVE TREATMENT OF DDH." Orthopaedic Proceedings. No. SUPP_III. The British Editorial Society of Bone \& Joint Surgery, 2002;84.

8. Qadir I, Ahmad S, Zaman AU, Khan CM, Ahmad S, Aziz A. One-stage hip reconstruction for developmental hip dysplasia in children over 8 years of age. Hip Pelvis. 2018;30(4):260-8.

9. Iyetin Y, Turkmen I, Saglam Y, Akcal MA, Unay K, Unsac B. A modified surgical approach of the hip in children: is it safe and reliable in patients with developmental hip dysplasia? J Child Orthop. 2015;9(3):199-207.

10. Cheung, JPY, Chow W, To M. Osteonecrosis and femoro acetabular impingement: sequelae of developmental dysplasia of the hip. BMJ Case Rep. 2012(2012):bcr1220115455.

11. Forlin E, Munhoz da Cunha LA, Figueiredo DC. Treatment of developmental dysplasia of the hip after walking age with open reduction, femoral shortening, and acetabular osteotomy. Orthoped Clin North Am. 2006;37(2): 149-60 vi.

12. Glorion C. Surgical reduction of congenital hip dislocation. Orthop Traumatol. 2018;104(1, Supplement):S147-57.

13. Gutiérrez Carbonell P. Arthrodiastasis followed by open reduction associated with pelvic and femoral osteotomies for the treatment of high inveterate congenital hip dislocation. J Pediatr Orthop B. 2018;27(6):479-84.

14. Lejman T, Strong M, Michno P. Capsulorrhaphy versus capsulectomy in open reduction of the hip for developmental dysplasia. J Pediatr Orthop. 1995; 15(1):98-100

15. Herring J. Tachdjian's Pediatric Orthopaedics. Philadelphia London New York St Louis Sydney Toronto: WB Saunders; 2002.

16. Pun S. Hip dysplasia in the young adult caused by residual childhood and adolescent-onset dysplasia. Curr Rev Musculoskelet Med. 2016;9(4):427-34.

17. Rosenbaum DG, Servaes S, Bogner EA, Jaramillo D, Mintz DN. MR imaging in Postreduction assessment of developmental dysplasia of the hip: goals and obstacles. RadioGraphics. 2016;36(3):840-54.

18. Aghaghazvini L, et al. Sonography: a sensitive and specific method for detecting trochlear cartilage pathologies. J Ultrasound. 2020;23.3:259-63.

19. Race C, Herring JA. Congenital dislocation of the hip: an evaluation of closed reduction. J Pediatr Orthop. 1983;3(2):166-72.

20. Weinstein SL, Mubarak SJ, Wenger DR. Fundamental concepts of developmental dysplasia of the hip. Instr Course Lect. 2014;63:299-305.
21. McCluskey WP, Bassett GS, Mora-Garcia G, MacEwen GD. Treatment of failed open reduction for congenital dislocation of the hip. J Pediatr Orthop. 1989; 9(6):633-9.

22. Sankar WN, Young CR, Lin AG, Crow SA, Baldwin KD, Moseley CF. Risk factors for failure after open reduction for DDH: a matched cohort analysis. J Pediatr Orthop. 2011;31(3):232-9.

23. Ludloff $K$. The open reduction of the congenital hip dislocation by an anterior incision. JBJS. 1913;2(3):438-54.

24. Alter AH: Primary open reduction of congenital dislocation of the hip, using median adductor approach: AB Ferguson. J. Bone Joint Surg. 55A 671-689 (June), 1973. Journal of Pediatric Surgery 1974, 9(2):270.

25. Troliæ Z, Ljubiæ B, Gavrankapetanoviæ I, Prliæ J, Moro G, Latinciæ A. Open reduction of congenital hip dislocation by medial approach: case series. Croat Med J. 2002;43:312-8.

26. Vitale MG, Skaggs DL. Developmental dysplasia of the hip from six months to four years of age. JAAOS. 2001;9(6):401-11.

27. Sener M, Baki C, Aydin H, Yildiz M, Saruhan S. The results of open reduction through a medial approach for developmental dysplasia of the hip in children above 18 months of age. Acta Orthop Traumatol Turc. 2004;38(4): 247-51.

28. Johari A, Wadia F. Revision surgery for developmental dysplasia of the hip Indian J Orthopaed. 2003:37(4):233.

29. Salter RB. Role of innominate osteotomy in the treatment of congenital. J Bone Joint Surg Am. 1966;48:1413-39.

30. Morcuende JA, Meyer MD, Dolan LA, Weinstein SL. Long-term outcome after open reduction through an anteromedial approach for congenital dislocation of the hip. JBJS. 1997;79(6):810-7.

31. Heep $\mathrm{H}, \mathrm{Xu}$ J, Löchteken C, Wedemeyer C. A simple and convenient method guide to determine the magnification of digital $X$-rays for preoperative planning in total hip arthroplasty. Orthop Rev (Pavia). 2012;4(1): e12.

32. Boese CK, Wilhelm S, Haneder S, Lechler P, Eysel P, Bredow J. Influence of calibration on digital templating of hip arthroplasty. Int Orthop. 2019;43(8): 1799-805.

33. Herring, John A. Tachdjian's pediatric orthopaedics e-book: from the Texas Scottish Rite Hospital for Children. Elsevier, 2020

\section{Publisher's Note}

Springer Nature remains neutral with regard to jurisdictional claims in published maps and institutional affiliations.

Ready to submit your research? Choose BMC and benefit from:

- fast, convenient online submission

- thorough peer review by experienced researchers in your field

- rapid publication on acceptance

- support for research data, including large and complex data types

- gold Open Access which fosters wider collaboration and increased citations

- maximum visibility for your research: over $100 \mathrm{M}$ website views per year

At $\mathrm{BMC}$, research is always in progress.

Learn more biomedcentral.com/submissions 